\title{
Women and Men National Collegiate Athletic Association Ice Hockey Players Were Similarly Likely to Suffer Lumbar Spine Injuries
}

\author{
Anna S. Jenkins, B.S., Jordan R. Pollock, B.S., Sailesh V. Tummala, M.D., \\ Joseph C. Brinkman, M.D., Merritt C. Kropelnicki, B.S., Justin L. Makovicka, M.D., M.B.A., \\ Jeffrey D. Hassebrock, M.D., and Anikar Chhabra, M.D.
}

\begin{abstract}
Purpose: To describe and compare the epidemiology of lumbar spine injuries (LSIs) in women's and men's ice hockey during the 2009-2010 to 2013-2014 academic years and to investigate sex-specific differences, using data from the National Collegiate Athletic Association (NCAA) Injury Surveillance Program (ISP) database. Methods: The incidence and characteristics of LSIs were identified utilizing the NCAA ISP. Rates of injury were calculated as number of injuries divided by total number of athlete exposures (AEs). AEs were defined as any student participation in one NCAA-sanctioned practice or competition. Incidence rate ratios (IRRs) were calculated to compare rates of injury between season, event type, mechanism, injury recurrence, and time lost from sport, and injury proportion ratios (IPRs) were calculated to examine the differences in injury rates between men and women. Results: There were a total of 165 LSIs from an average of 10 and 19 women's and men's teams, respectively, calculated to 1,254 LSIs nationally. Women were 2.48 times more likely to suffer a noncontact injury than men (95\% CI: 1.33-4.61), whereas men were more likely than women to suffer contact LSIs (IPR: .51 [95\% CI: .28-.92]). In Divisions II and III, women were 6.64 (95\% CI: 4.14-10.64) and 1.28 (95\% CI: 1.12-1.46) times more likely to suffer LSIs than men, respectively. Conclusions: Women and men were similarly likely to suffer an LSI, but sex-specific differences existed in a mechanism of injury and likelihood of injury within NCAA Divisions.
\end{abstract}

\section{Introduction}

$\mathbf{I}$ ce hockey has grown in popularity over the past two decades within the National Collegiate Athletic Association (NCAA), with the number of total athletes more than doubling for women between 1999 and 2020. ${ }^{1}$ Ice hockey is known for its high-speed collisions, and injury is

From the Mayo Clinic Alix School of Medicine, Mayo Clinic, Scottsdale, Arizona, U.S.A. (A.S.J., J.R.P., J.L.M); and Department of Orthopedic Surgery, Mayo Clinic, Phoenix, Arizona, U.S.A. (S.V.T., J.C.B., J.D.H., A.C.); and UT Southwestern Medical School, Dallas, Texas, U.S.A. (M.C.K.).

The authors report the following potential conflicts of interest or sources of funding: A.C. serves as a consultant and speaker's bureau for Anthrex Z, and as a consultant for Zimmer-Biomet and Trice Medical, outside the submitted work. Full ICMJE author disclosure forms are available for this article online, as supplementary material.

Received May 23, 2021; accepted September 21, 2021.

Address correspondence to Anikar Chhabra, M.D., Department of Orthopaedic Surgery, Mayo Clinic Arizona, 5777 E. Mayo Blvd., Phoenix, AZ, 85054, U.S.A.E-mail:Chhabra.anikar@mayo.edu

(C) 2021 THE AUTHORS. Published by Elsevier Inc. on behalf of the Arthroscopy Association of North America. This is an open access article under the CC BY-NC-ND license (http://creativecommons.org/licenses/by-nc-nd/4.0/).

2666-061X/21738

https://doi.org/10.1016/j.asmr.2021.09.016 a common occurrence, particularly for women. ${ }^{2-4}$ Between 2009 and 2014, injuries occurred at rates of 9.5 and 6.1 per 1,000 athlete exposures (AE) in women's and men's college hockey, respectively (an AE representing any student participation in one NCAA-sanctioned practice or competition). ${ }^{1}$ These represent particularly high injury rates within college athletics: only men's football, men's wrestling, and women's gymnastics saw higher injury rates per 1,000 AEs. ${ }^{5}$

Injuries to the lumbar spine present a particular threat to ice hockey players. Players spend much of their time in bent-over positions, frequently pivoting and rotating their lower backs, and lumbar spine injuries (LSIs) are a common source of injury, including contusions, dislocations, fractures, spasms, strains, spinal injuries, and miscellaneous sources of pain in the low back. ${ }^{6-9}$ LSIs can persist and lead to significant morbidity or missed participation, and proper, timely treatment of these injuries is essential to recovery. ${ }^{2,9}$ Prior work comparing rates of LSIs across 25 NCAA sports suggests that LSIs occur more commonly in ice hockey than the majority of other college sports. ${ }^{10}$ Comparing men's sports, only tennis saw higher rates of LSIs. For women, 
only gymnastics, tennis, and volleyball saw higher rates. ${ }^{10}$

Prior work has described epidemiology of back, neck, and spine injuries in NCAA ice hockey players; it found that the lumbar spine was the most common site of injury, and that risk of injury was similar for men and women. ${ }^{8}$ The finding that men and women face similar risk of back injury is somewhat surprising as women's college ice hockey does not allow for body checking, a major source of injury. ${ }^{2,3,6,7}$ There is also a paucity of work exploring why, despite more restrictive regulations, women ice hockey players suffer similar rates of injury compared to men. Although sex-specific epidemiology of LSIs has been examined in other college sports such as basketball, the literature describing these injuries in hockey players is sparce. ${ }^{8,11}$

The purposes of our study were to describe and compare the epidemiology of LSIs in women's and men's ice hockey during the 2009-2010 to 2013-2014 academic years and to investigate sex-specific differences, using data from the National Collegiate Athletic Association (NCAA) Injury Surveillance Program (ISP) database. We hypothesized that sex-specific differences exist between men's and women's ice hockey and that these differences reflect the more restrictive checking regulations in women's ice hockey. Specifically, we predict that women ice hockey players are less likely than men to be injured due to competition-related player-to-player contact but are more likely to be injured from noncontact injuries of overuse.

\section{Methods}

\section{Data Collection}

The NCAA ISP database is a validated resource that has been previously used to report injuries in collegiate athletes. ${ }^{10-19}$ After receiving IRB approval (IRB: \#17008147) from the home institution, this database was used to evaluate data from the 2009-2010 to 2013-2014 academic years on LSIs in college ice hockey.

The NCAA ISP is a prospectively gathered injury surveillance program, which is managed by the Datalys Center for Sports Injury Research and Prevention. This study was found to be institutional review board exempt and approved by the research review board of the NCAA.

The use of the NCAA ISP has been extensively described in previous works. ${ }^{18,20}$ The NCAA ISP uses a voluntary convenience sample of NCAA programs over a 5 -year period, with varying annual program participation. ${ }^{15,20}$ This provides a deterministic sample of college athletes, which has been used to monitor trends and patterns in injuries. ${ }^{13}$

Data are provided through institutional electronic health records and recorded by athletic trainers (ATs) at each participating program. Data are collected throughout pre-, post-, and regular seasons. ATs and/or physicians

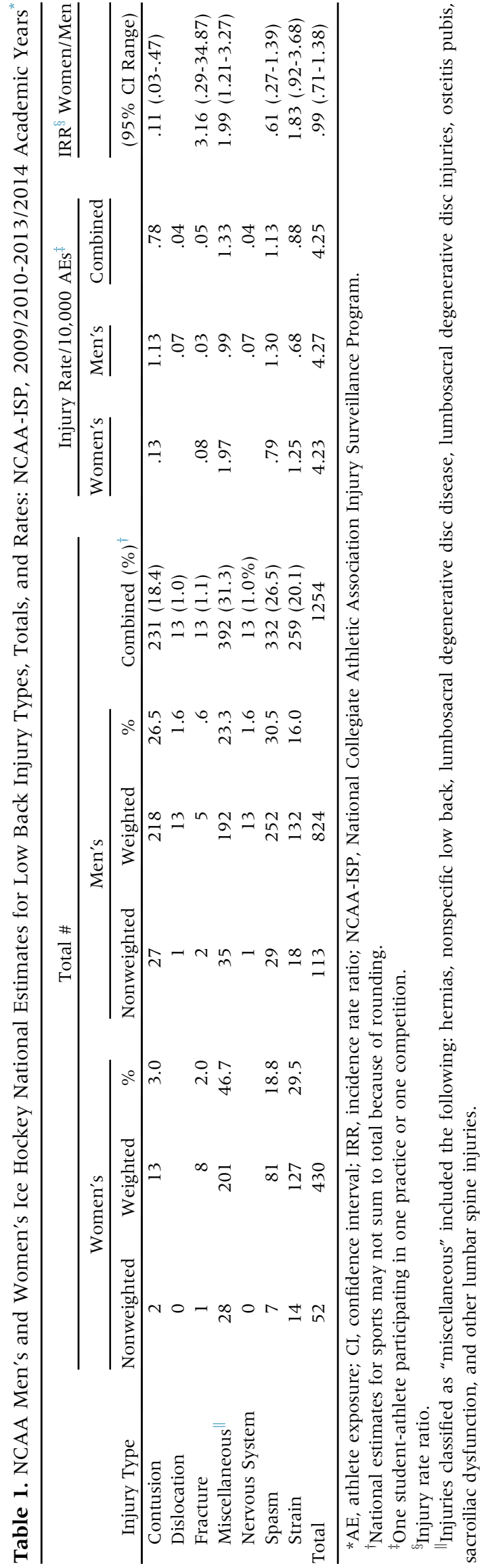


record a detailed report of each injury and the number of student athletes participating in each practice and competition, which is used to compute the number of athletic exposures. The database was queried for women's and men's ice hockey players who sustained a "low back injury" or LSI. Most recently updated diagnoses were used.

\section{Computing National Estimates}

The method used to calculate national estimates of injuries has been previously described. ${ }^{12,18,21}$ Poststratification sample weights were calculated with the following formula: sample weight $=$ $\left(\frac{\text { number of teams participating in the ISP } P_{a b c}}{\text { Number of teams in the } N C A A_{a b c}}\right)^{-1}$, where weight $t_{a b c}$ is the weight for the ath sport of the $b$ th division in the $c$ th year. ${ }^{15,17,22}$ Weights for all data were further adjusted to correct for underreporting, accounting for the estimated $88.3 \%$ capture rate of all time-loss medical care injury events with the NCAA ISP. ${ }^{12}$ Weighting varied on the basis of sport, exposure type, division played, and calendar year.

\section{Data Analysis}

Data were analyzed to assess the rates and patterns of LSIs sustained in women and men ice hockey players within the NCAA. ${ }^{12}$ LSIs were analyzed for injury type, time lost from participation, time of season, event type, recurrence, injury mechanism, and resulting participation restriction. Injuries classified as "miscellaneous" included the following: hernias, nonspecific low back, lumbosacral degenerative disc disease, lumbosacral degenerative disc injuries, osteitis pubis, sacroiliac dysfunction, and other lumbar spine injuries.

The injury rate was defined as the number of injuries divided by the number of AEs, and an AE was defined as any student athlete participation in one NCAAsanctioned practice or competition. The rates were reported as the ratio of injuries per 10,000 AEs and calculated as an overall rate, as well as individual rates for event type (practice vs competition) and time of season (preseason, regular season, and postseason). Incidence rate ratios (IRRs) were calculated to compare the rates between event types and times of the season. The following is an example of an IRR comparing injury rates between competition and practice: ${ }^{12}$

$I R R=\frac{\left(\frac{\sum \text { Number of competition injuries }}{\sum \text { Competition AEs }}\right)}{\left(\frac{\sum \text { Number of practice injuries }}{\sum \text { Practice } A E s}\right)}$

Injury proportion ratios (IPRs) were calculated to examine the differences in injury rates between men's

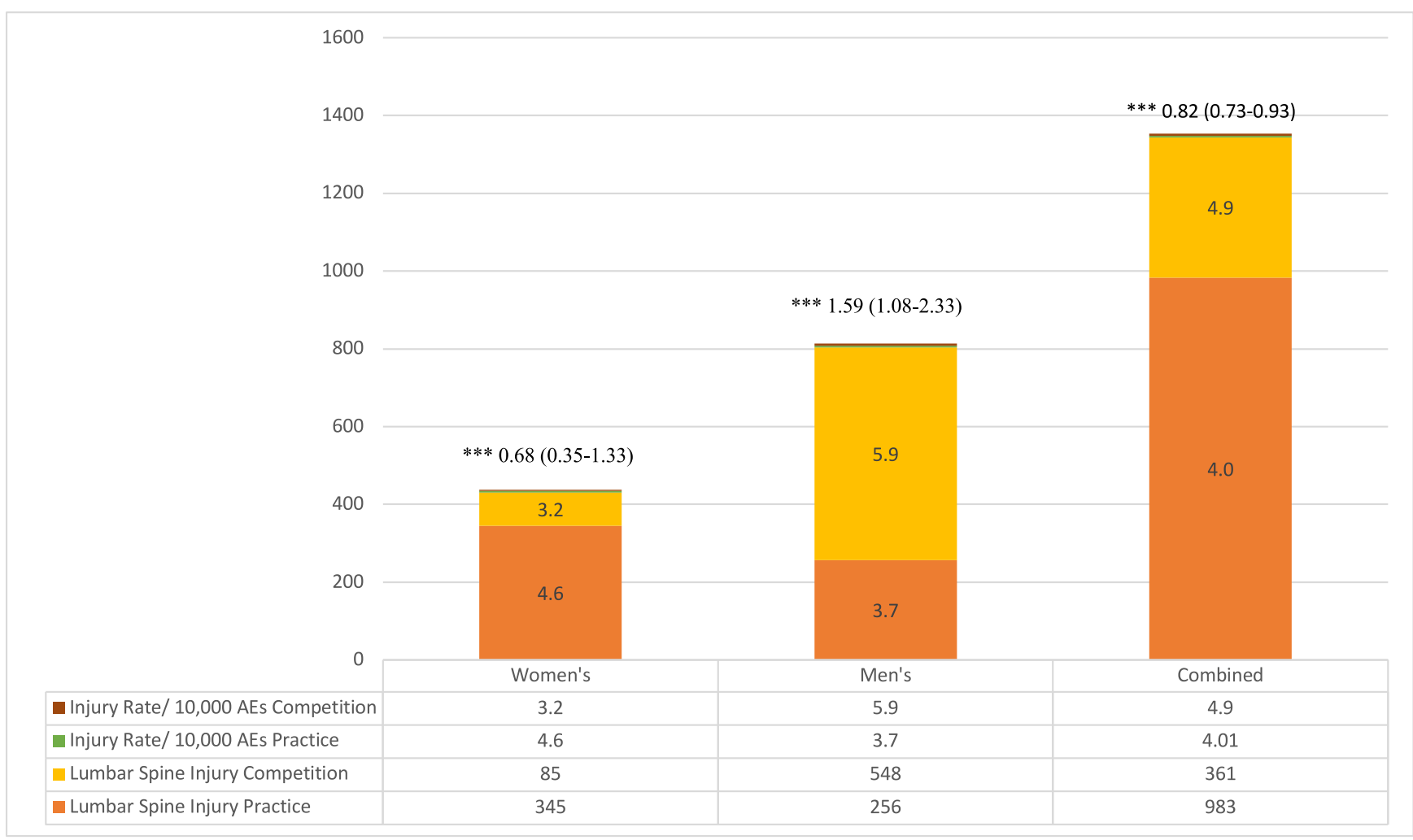

*** Competition/Practice Injury Risk Ratio (95\% Confidence Interval)

Fig 1. Injury occurrence in relation to practice and competitions: NCAA-ISP, 2009/2010-2013/2014. 
Table 2. Distribution of Estimated Injuries in Relation to Season of Play: NCAA-ISP, 2009/2010-2013/2014

\begin{tabular}{|c|c|c|c|c|c|c|c|}
\hline & \multicolumn{2}{|c|}{ Women's } & \multicolumn{2}{|c|}{ Men's } & \multicolumn{2}{|c|}{ Combined } & $\begin{array}{c}\text { IPR } \\
\text { Women/Men } \\
(95 \% \mathrm{CI})\end{array}$ \\
\hline In-Season & 293 & 3.6 & 638 & 4.1 & 931 & .4 & $.88(.61-1.29)$ \\
\hline \multirow[t]{2}{*}{ Postseason } & 0 & 0 & 11 & .8 & 11 & .1 & \\
\hline & & \multicolumn{2}{|c|}{ Women's IRR $(95 \%$ CI) } & \multicolumn{2}{|c|}{ Men's IRR $(95 \%$ CI) } & \multicolumn{2}{|c|}{ Combined IRR $(95 \%$ CI } \\
\hline Postseason/1 & 1-Season & \multirow{2}{*}{\multicolumn{2}{|c|}{$2.73(1.46-5.11)$}} & \multicolumn{2}{|c|}{$.20(.06-.64)$} & \multicolumn{2}{|c|}{$.14(.08-.26)$} \\
\hline \multicolumn{2}{|c|}{$\begin{array}{l}\text { Postseason/In-Season } \\
\text { Preseason/In-Season }\end{array}$} & & & \multicolumn{2}{|c|}{$1.88(1.19-2.98)$} & \multicolumn{2}{|c|}{$2.17(1.91-2.47)$} \\
\hline
\end{tabular}

AE, athlete exposure; CI, confidence interval; IRR, incidence rate ratio; NCAA-ISP, National Collegiate Athletic Association Injury Surveillance Program

and women's ice hockey players. IPRs were consistently calculated with men in the denominator. The following is an example of an IPR comparing the proportion of lower back injuries caused by contusion between men and women:

$I P R=\left(\frac{\left(\frac{\sum \text { contusion in women }}{\sum \text { total LSIs in women }}\right)}{\left(\frac{\sum \text { contusion in men }}{\sum \text { total LSIs in men }}\right)}\right)$

Participation restriction time was reported as intervals ( $<24$ hours, 1-6 days, 7-21 days, and $>21$ days), and descriptive data were presented as percentages of injuries. Data were analyzed using SPSS software (IBM) and Excel (Microsoft).

\section{Results}

In the setting of collegiate ice hockey, 52 LSIs in women and 113 LSIs in men were identified in the NCAA ISP database during the 2009-2010 to 2013-2014 academic years. This represents a national estimate of 430 LSIs in women and 824 LSIs in men (Table 1). The overall LSI rate for athletes was 4.3 per 10,000 AEs. The LSI rate was 4.2 per 10,000 AEs in women and 4.3 LSI per 10,000 AEs in men. Women were just as likely to suffer LSIs as men (IPR: .99 [95\% CI: .71-11.38]).

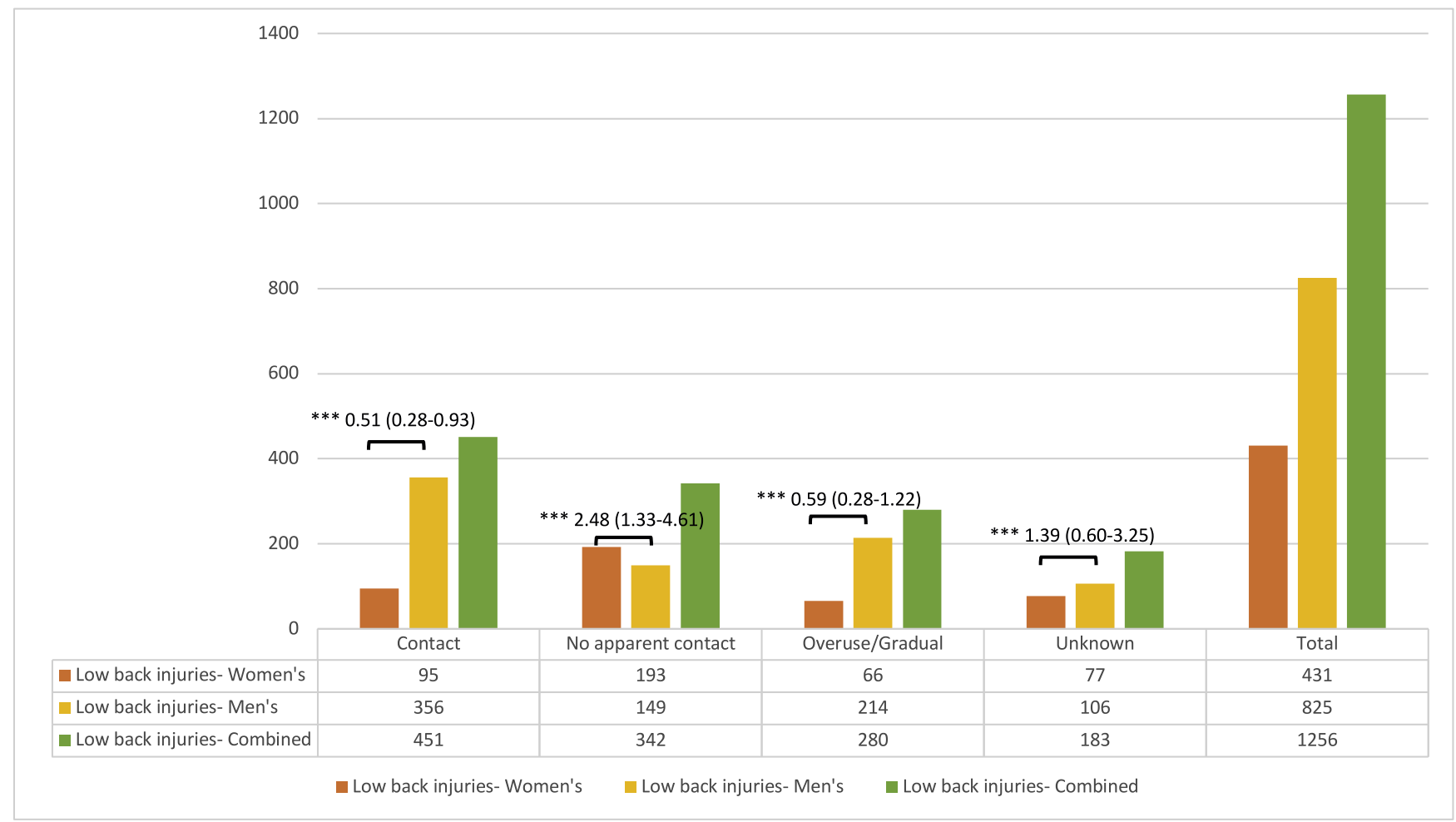

*** Women/Men Injury Proportion Ratio (95\% Confidence Interval)

Fig 2. NCAA men's and women's ice hockey comparison of mechanism of low back injury: NCAA-ISP, 2009/2010-2013/2014. 


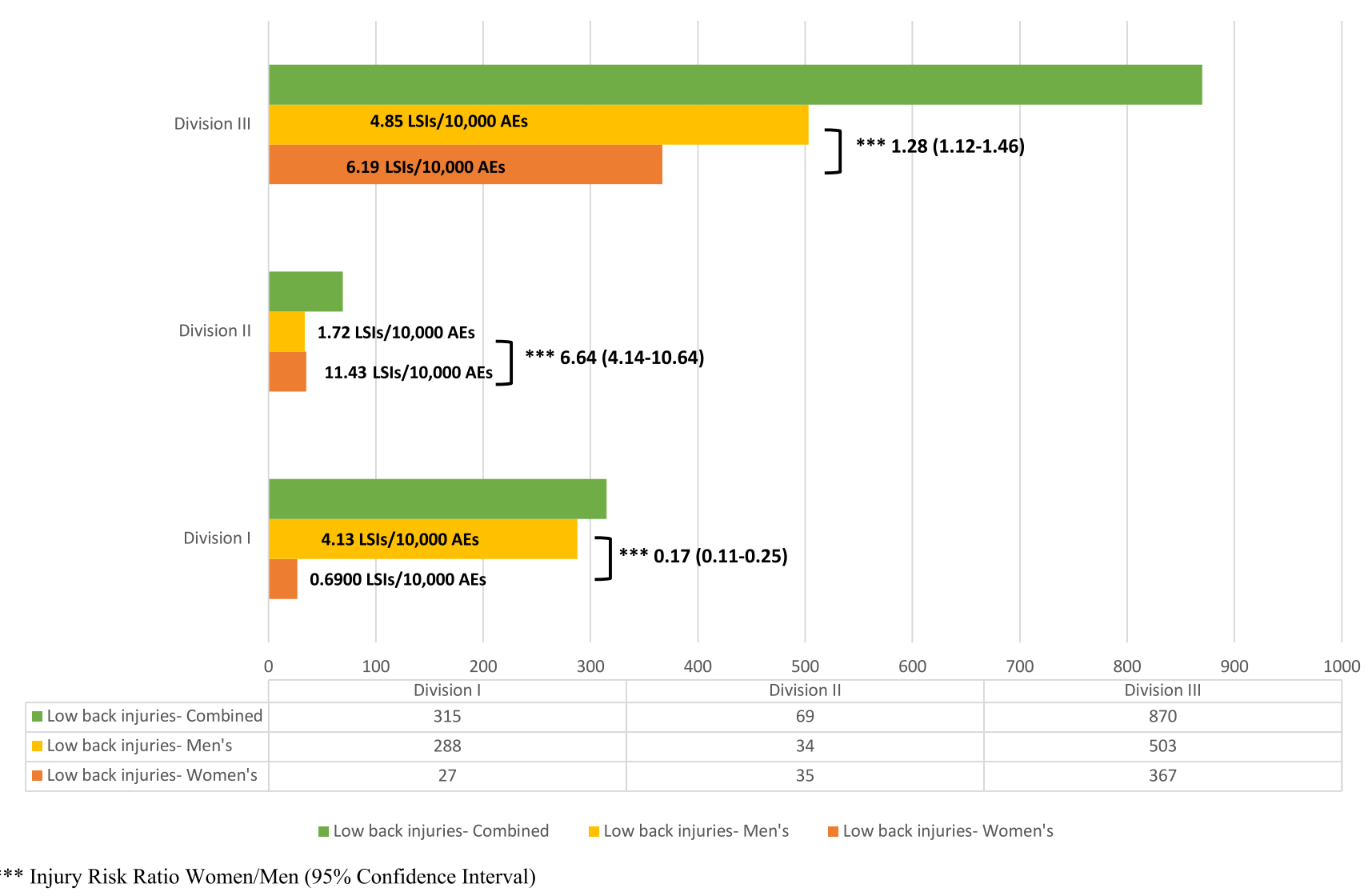

Fig 3. NCAA Ice Hockey injuries estimates by division: NCAA-ISP, 2009/2010-2013/2014.

\section{Event Type and Time of Season}

The LSI rate in women per 10,000 AEs was 3.2 for competition and 4.6 for practice; for men it was 5.9 and 3.7, respectively (Fig 1). Men were 1.59 times more likely to be injured during competition than practice (95\% CI: 1.08-2.33), whereas women faced no greater risk during competition (IRR: .68 [95\% CI: .72-1.33). The highest rate of injury was during the preseason for both women $(9.8 / 10,000$ AEs) and men $(7.7 / 10,000$ AEs) (Table 2). Women were 2.73 times more likely to be injured during the preseason than in-season $(95 \%$ CI: 1.46-5.11); men were 1.88 times more likely to be injured during preseason than in-season $(95 \% \mathrm{CI}$ : 1.19-2.98).

\section{Mechanism of Injury}

Although women and men were equally likely to suffer LSIs overall, there were differences in the mechanism of women's and men's injuries. Noncontact injuries were the most common mechanism of injury in women $(44.8 \% ; n=193)$, whereas contact injuries were the most common in men $(43.2 \% ; n=356)$ (Fig 2). Women were 2.48 times more likely than men to suffer noncontact LSIs (95\% CI: 1.33-4.61), whereas men were nearly twice as likely as women to suffer contact LSIs (IPR: .51 [95\% CI: .28-.92]).

\section{Injury by Division}

Comparing injury rates between NCAA divisions, Division II women suffered the highest rates of LSIs, experiencing 11.43 compared to 6.19 and .69 LSIs per 10,000 AEs for Divisions III and Division I women, respectively. Women in Division II were 16.65 times more likely to suffer an LSI than Division I players (95\% CI: 10.08-27.50). Injury rates within men's hockey were greatest in Division III, with 4.85 LSIs per 10,000 AEs compared to 4.13 and 1.72 LSIs per 10,000 AEs for Divisions I and II, respectively (Fig 3). There were significant differences between sexes when comparing risk of injury within divisions. Within Division I, men were 6.25 times more likely than women to suffer LSIs (IPR: .17 [95\% CI: .11-.25]). In contrast, women were 6.64 times more likely than men to suffer LSIs within Division II (95\% CI: 4.14-10.64), and 1.28 times more likely within Division II (95\% CI: 1.12-1.46).

\section{Injury by Position}

Players in the defensive positions suffered more LSIs than players of any other position, both in women's $(38.8 \% ; n=167)$ and men's $(37.1 \% ; n=306)$ ice hockey (Fig 4). Male wings were more likely to suffer an LSI than their female counterparts (IPR: .26 [95\% CI: .08-.87]). 
1400

1200

1000

800

600

400

$0 * * * 1.04(0.61-1.79)$

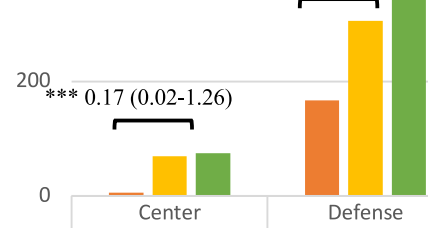

$* * * 1.02(0.52-1.97)$

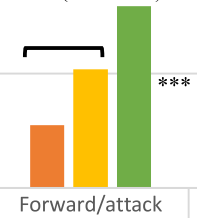

n Low back injuries- Women's

- Low back injuries- Men's

- Low back injuries- Combined

\begin{tabular}{|c|c|}
\hline 6 & Defense \\
\hline 69 & 167 \\
\hline 75 & 306 \\
\hline
\end{tabular}

Low back injuries- Women's

orward/attack

110

207

317

Low back injurit

n Low back injuries- Combined

*** Women/Men Injury Proportion Ratio (95\% Confidence Interval)

Fig 4. NCAA Ice Hockey Injury by Position: NCAA-ISP, 2009/2010-2013/2014.

\section{Time Lost from Injury and Injury Recurrence}

The majority of both women $(71.6 \% ; n=305)$ and men $(70.2 \% ; n=553)$ who suffered an LSI were able to return to play within 24 hours of injury (Tables 3 and 4 ). Less than $1 \%(.9 \% ; n=4)$ of women and $2.9 \%(n=23)$ of men were unable to return to play after 3 weeks. Overall, $70.2 \%(n=302)$ of LSIs in women and $80.8 \%$ $(n=666)$ of LSIs in men were new injuries; $29.8 \%$ $(n=128)$ of LSIs in women and $19.2 \%(n=158)$ of LSIs in men were recurrent injuries (Table 5 ).

\section{Discussion}

Lower back injuries are known to be a common source of injury for ice hockey players but have not been specifically studied in college players. ${ }^{3,6-8,23}$ Our study found an LSI occurrence rate of 4.2 per 10,000 AEs in women and 4.3 LSI per 10,000 AEs in men. This was similar to previously reported rates. ${ }^{10}$ In comparison with other sports, the observed rate of LSIs in college hockey players was generally greater than that reported for other college sports, with the exception of men's and women's tennis and women's gymnastics, tennis, and volleyball. ${ }^{10-12}$

Our analyses suggest that women ice and men ice hockey players face a similar likelihood of suffering LSIs. This aligns with prior reports of equal rates of back, neck, and spine injuries and concussions in women and men college ice hockey players, ${ }^{8,23}$ yet it is somewhat surprising because of differing regulations outlawing body checking in women's college ice hockey. As checking presents a major source of injury, one would expect this regulation to result in lower injury rates in women's ice hockey compared to men. ${ }^{2,3,6,7}$ One potential explanation of how women's ice hockey players suffer equal rates of LSIs compared to men despite more restrictive safety regulations is that the regulations are ineffective at preventing checking and resulting contact injuries. This theory would align with prior research, indicating that player-contact remains the prevailing cause of injury in women's hockey, yet it is not supported by our data. ${ }^{6-8}$

Table 3. Time Loss Comparison: NCAA-ISP, 2009/20102013/2014

\begin{tabular}{lccccc}
\hline & \multicolumn{3}{c}{ Low Back Injuries, $n(\%)$} & & IPR $(95 \%$ CI $)$ \\
\cline { 2 - 3 } & Women's & Men's & Combined & & Women/Men \\
\hline$<24$ Hours & $305(71.6)$ & $553(70.2)$ & $858(70.7)$ & & $1.02(.68-1.54)$ \\
1-6 Days & $74(17.4)$ & $188(23.9)$ & $262(21.6)$ & & $.73(.35-1.51)$ \\
7-2 1 Days & $43(10.1)$ & $24(3.0)$ & $67(5.5)$ & & $3.31(.94-11.74)$ \\
$>21$ Days & $4(.94)$ & $23(2.9)$ & $27(2.2)$ & & $.32(.04-2.67)$ \\
Total & 426 & 788 & 1,214 & \\
\hline
\end{tabular}

CI, confidence interval; IPR, injury proportion ratio; NCAA-ISP, National Collegiate Athletic Association Injury Surveillance Program. 


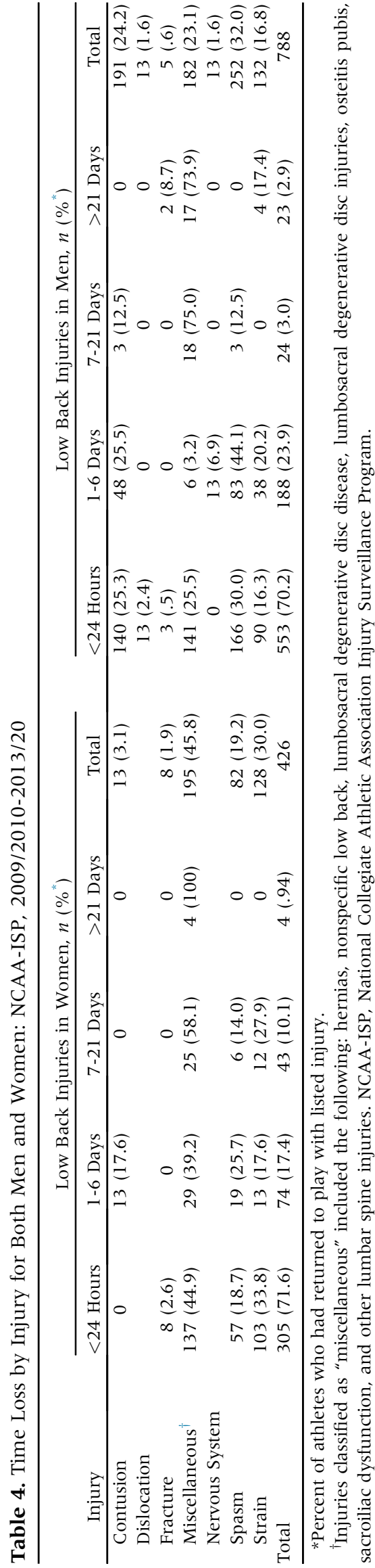

Supporting the effectiveness of checking regulations, we found that women were more likely to suffer noncontact LSIs than contact LSIs, whereas men, without such regulations, were more likely to suffer contact than noncontact LSIs and were nearly twice as likely as women to suffer contact LSIs.

The question remains why women face an overall equal risk of LSIs, as compared to men, despite a lower risk of contact injuries. Our analyses suggest a source of increased injury risk for women is noncontact LSIs. We found that women were 2.48 times more likely than men to suffer noncontact LSIs. Further research is needed to elucidate why rates of noncontact LSIs are higher in women's college ice hockey than men's. Future work might explore similarities between injury epidemiology of women's college ice hockey and gymnastics, tennis, and volleyball, as these noncontact sports similarly report a high occurrence of LSIs in women. ${ }^{10}$

Further sex-specific differences in injury risk were identified when we looked at LSIs within Divisions. We found that Division II and III women ice hockey players faced a 6.64 and 1.28 times greater risk of LSIs than their male counterparts, respectively. Further research might explore whether differences between men's and women's Division II and III ice hockey programs exist that explain the observed increased rates of LSIs for women.

Although rates of LSIs in women were greatest in Division II ice hockey, in men they were greatest in Division III. Reports of injury likelihood between NCAA divisions in ice hockey is mixed, with some studies indicating equal rates of injury and others finding highest rates in Division I. ${ }^{6-8}$ More research is needed to better understand what might be causing the observed discrepancies in injury risk between divisions.

We found that women were not more likely to suffer LSIs during competition than practice, contrasting prior reports of injury epidemiology. ${ }^{3,6-8}$ Aligning with the prior work, men were more likely to be injured during competition than practice. ${ }^{3,6-8}$ As with prior work, we found that LSIs were more likely during preseason than regular season for both sexes. ${ }^{7,8,23}$ This trend is similar to that of other NCAA sports, but it merits further investigation to evaluate the effectiveness of implementing injury-prevention programs early during preseason. ${ }^{10}$

Aligning with prior reports of injuries in college ice hockey, the majority of players in this sample suffering LSIs returned to play within 24 hours. ${ }^{7,23}$ We found that injury was the result of recurrence for $29.8 \%$ and $19.2 \%$ of injuries for women and men, respectively. One possible explanation for little time lost but frequent rates of recurrence is that less rigorous injury prevention in the NCAA contributes to frequent, lower severity injuries with high likelihood of recurrence. Alternatively, NCAA players may be allowed to return to play before sufficient time for full recovery, resulting in shorter time lost but greater risk of reinjury. 
Table 5. NCAA Men's and Women's Ice Hockey Comparison of Injury Recurrence: NCAA-ISP, 2009/2010-2013/2014

\begin{tabular}{lccccr}
\hline & \multicolumn{3}{c}{ Low Back Injuries, $n\left(\%^{*}\right)$} & & \multirow{2}{*}{ IPR $(95 \% \mathrm{CI})$} \\
\cline { 2 - 3 } & Women's & Men's & Combined & & Women/Men \\
\hline New Injury & $302(70.2)$ & $666(80.8)$ & $968(77.2)$ & $.87(.59-1.27)$ \\
Recurrent Injury & $128(29.8)$ & $158(19.2)$ & $286(22.8)$ & & $1.55(.81-2.95)$
\end{tabular}

*Percent of athletes who had returned to play with listed injury. CI, confidence interval; IPR, injury proportion ratio; NCAA-ISP, National Collegiate Athletic Association Injury Surveillance Program.

\section{Limitations}

While the NCAA-ISP provides a long-standing, reputable reporting system of injury in college athletes, it is not without its limitations. As a convenience sample of varying annual size, there is potential for overestimation and underestimation of actual injury incidence and weighting of data introduces potential for error. Voluntary participation in the database may introduce selection bias. Furthermore, accuracy in data entry depends on AT's compliance, and errors are possible. The NCAA ISP's predefined diagnostic criteria do not include imaging, and AT bias may introduce inconsistencies in diagnoses. Finally, the infrequency of certain injuries and smaller size of certain Divisions resulted in low numbers and underpowering of specific analyses.

\section{Conclusion}

Women and men were similarly likely to suffer an LSI, but sex-specific differences existed in mechanism of injury and likelihood of injury within NCAA Divisions.

\section{Acknowledgment}

This publication contains materials created, compiled, or produced by the Datalys Center for Sports Injury Research and Prevention on behalf of the National Collegiate Athletic Association (NCAA). (C2019 National Collegiate Athletic Association. All rights reserved. The NCAA Injury Surveillance Program (ISP) data were provided by the Datalys Center. The ISP was funded by the NCAA. The content of this article is solely the responsibility of the authors and does not necessarily represent the official views of the Datalys Center or the NCAA. The authors thank the many athletic trainers who have volunteered their time and efforts to submit data to the NCAA ISP. Their efforts are greatly appreciated and have had a tremendously positive effect on the safety of collegiate athletes.

\section{References}

1. Irick E. NCAA Sports Sponsorship and Participation Rates Report. National Collegiate Athletic Association, 2019, https://ncaaorg.s3.amazonaws.com/research/sportpart/ 2018-19RES_SportsSponsorshipParticipationRatesReport. pdf. Accessed January 30, 2021.
2. Berube ER, Lopez CD, Trofa DP, Popkin CA. A systematic review of the orthopedic literature involving National Hockey League Players. Open Access J Sports Med 2020;11: 145-160. doi:10.2147/OAJSM.S263260.

3. Anderson GR, Melugin HP, Stuart MJ. Epidemiology of injuries in ice hockey. Sports Health Multidiscip Approach 2019;11:514-519. doi:10.1177/1941738119849105.

4. McKay CD, Tufts RJ, Shaffer B, Meeuwisse WH. The epidemiology of professional ice hockey injuries: A prospective report of six NHL seasons. $\mathrm{Br} \mathrm{J}$ Sports Med 2014;48:57-62. doi:10.1136/bjsports-2013-092860.

5. Kerr ZY, Marshall SW, Dompier TP, Corlette J, Klossner DA, Gilchrist J. College sports-related injuries-United States, 2009-10 through 2013-14 academic years. Morb Mortal Wkly Rep 2015;64:1330-1336.

6. Agel J, Dick R, Nelson B, Marshall SW, Dompier TP. Descriptive epidemiology of collegiate women's ice hockey injuries: National Collegiate Athletic Association Injury Surveillance System, 2000-2001 through 20032004. J Athl Train 2007;42:249-254.

7. Agel J, Dompier TP, Dick R, Marshall SW. Descriptive epidemiology of collegiate men's ice hockey injuries: National Collegiate Athletic Association Injury Surveillance System, 1988-1989 through 2003-2004. J Athl Train 2007;42:241-248.

8. Zupon AB, Kerr ZY, Dalton SL, Dompier TP, Gardner EC. The epidemiology of back/neck/spine injuries in National Collegiate Athletic Association men's and women's ice hockey, 2009/2010 to 2014/2015. Res Sports Med 2018;26: 13-26. doi:10.1080/15438627.2017.1365295.

9. Ball JR, Harris CB, Lee J, Vives MJ. Lumbar spine injuries in sports: Review of the literature and current treatment recommendations. Sports Med Open 2019;5:26. doi:10. 1186/s40798-019-0199-7.

10. Hassebrock JD, Patel KA, Makovicka JL, et al. Lumbar spine injuries in National Collegiate Athletic Association Athletes: A 6-season epidemiological study. Orthop J Sports Med 2019;7: 232596711882004. doi:10.1177/2325967118820046.

11. Makovicka JL, Deckey DG, Patel KA, et al. Epidemiology of lumbar spine injuries in men's and women's National Collegiate Athletic Association basketball athletes. Orthop $J$ Sports Med 2019;7:232596711987910. doi:10.1177/ 2325967119879104.

12. Makovicka JL, Patel KA, Deckey DG, et al. Lower back injuries in National Collegiate Athletic Association Football Players: A 5-season epidemiological study. Orthop J Sports Med 2019;7:232596711985262. doi:10.1177/ 2325967119852625.

13. Dragoo JL, Braun HJ, Bartlinski SE, Harris AHS. Acromioclavicular joint injuries in National Collegiate Athletic Association football: Data from the 2004-2005 through 2008-2009 National Collegiate Athletic Association Injury Surveillance System. Am J Sports Med 2012;40:2066-2071. doi: $10.1177 / 0363546512454653$.

14. Dragoo JL, Braun HJ, Durham JL, Chen MR, Harris AHS. Incidence and risk factors for injuries to the anterior cruciate ligament in National Collegiate Athletic Association Football: Data from the 2004-2005 through 20082009 National Collegiate Athletic Association Injury Surveillance System. Am J Sports Med 2012;40:990-995. doi:10.1177/0363546512442336. 
15. Eckard TG, Padua DA, Dompier TP, Dalton SL, Thorborg K, Kerr ZY. Epidemiology of hip flexor and hip adductor strains in National Collegiate Athletic Association athletes, 2009/2010-2014/2015. Am J Sports Med 2017;45:2713-2722. doi:10.1177/0363546517716179.

16. Hootman JM, Dick R, Agel J. Epidemiology of collegiate injuries for 15 sports: summary and recommendations for injury prevention initiatives. $J$ Athl Train 2007;42: 311-319.

17. Kerr ZY, Simon JE, Grooms DR, Roos KG, Cohen RP, Dompier TP. Epidemiology of Football Injuries in the National Collegiate Athletic Association, 2004-2005 to 2008-2009. Orthop J Sports Med 2016;4:2325967 11666450. doi:10.1177/2325967116664500.

18. Tummala SV, Hartigan DE, Patel KA, Makovicka JL, Chhabra A. Shoulder injuries in National Collegiate Athletic Association quarterbacks: 10-Year epidemiology of incidence, risk factors, and trends. Orthop J Sports Med 2018;6: 232596711875682 . doi:10.1177/2325967118756826.

19. Westermann RW, Kerr ZY, Wehr P, Amendola A. Increasing lower extremity injury rates across the 2009-2010 to
2014-2015 seasons of National Collegiate Athletic Association Football: An unintended consequence of the "targeting" rule used to prevent concussions? Am J Sports Med 2016;44: 3230-3236. doi:10.1177/0363546516659290.

20. Kerr ZY, Dompier TP, Snook EM, et al. National Collegiate Athletic Association Injury Surveillance System: Review of methods for 2004-2005 through 2013-2014 data collection. J Athl Train 2014;49:552-560. doi:10.4085/ 1062-6050-49.3.58.

21. Tummala SV, Chhabra A, Makovicka JL, Patel KA, Hartigan DE. Hip and groin injuries among collegiate male soccer players: The 10-year epidemiology, incidence, and prevention. Orthopedics 2018;41:e831-e836. doi:10.3928/ 01477447-20181010-01.

22. Chung AS, Makovicka JL, Hassebrock JD, et al. Epidemiology of cervical injuries in NCAA football players. Spine 2019;44:848-854. doi:10.1097/BRS.0000000000 003008.

23. Agel J, Harvey EJ. A 7-year review of men's and women's ice hockey injuries in the NCAA. Can J Surg J Can Chir 2010;53:319-323. 